\title{
The effect of charge carrier and doping site on thermoelectric properties of $\mathrm{Mg}_{2} \mathrm{Sn}_{0.75} \mathrm{Ge}_{0.25}$
}

Udara Saparamadu ${ }^{\mathrm{a}}$, Jun Mao ${ }^{\mathrm{a}, \mathrm{b}}$, Keshab Dahal ${ }^{\mathrm{a}}$, Hao Zhang ${ }^{\mathrm{a}, \mathrm{c}}$, Fei Tian ${ }^{\mathrm{a}}$, Shaowei Song ${ }^{\mathrm{a}, \mathrm{d}}$, Weishu Liu ${ }^{\mathrm{a}, \mathrm{e}^{*}}$, and Zhifeng Ren ${ }^{\mathrm{a}^{*}}$

${ }^{a}$ Department of Physics and TcSUH, University of Houston, Houston, TX 77204, USA

${ }^{\mathrm{b}}$ Department of Mechanical Engineering, University of Houston, Houston, TX 77204, USA

${ }^{\mathrm{c}}$ Department of Chemistry and TcSUH, University of Houston, Houston, TX, 77204, USA

${ }^{\mathrm{d}}$ Program of Material Science and Engineering, University of Houston, Houston, TX, 77204, USA

e Department of Materials Science \& Engineering, South University of Science \& Technology of China, Shenzhen, Guangdong 518055, China

\begin{abstract}
$\mathrm{Mg}_{2} \mathrm{Sn}_{0.75} \mathrm{Ge}_{0.25}$ has been recently demonstrated to be a promising thermoelectric material for power generation in the temperature range from room temperature to $723 \mathrm{~K}$ because of the high power factor of $\sim 54 \mu \mathrm{W} \mathrm{cm}{ }^{-1} \mathrm{~K}^{-2}$ upon $\mathrm{Sb}$ doping to the $\mathrm{Sn}$ site. The enhanced density of states effective mass and weak electron scattering from the alloying effect are believed to be the main reasons for the high power factor $(P F)$ and hence high figure of merit $(Z T)$. In this study, it is shown that the right choice of carrier donor also plays an important role in obtaining high power
\end{abstract}


factor. The effect of carrier donors $\mathrm{Y}$ and $\mathrm{La}$ at $\mathrm{Mg}$-site and $\mathrm{Bi}$ and $\mathrm{P}$ at $\mathrm{Sn}$-site in $\mathrm{Mg}_{2} \mathrm{Sn}_{0.75} \mathrm{Ge}_{0.25}$ is systematically investigated. It is found that charge donors at the Sn-site are much more effective than at the Mg-site in enhancing $P F$ and ZT. Bi doped $\mathrm{Mg}_{2} \mathrm{Sn}_{0.73} \mathrm{Bi}_{0.02} \mathrm{Ge}_{0.25}$ shows a peak $Z T$ of $\sim 1.4$ at $673 \mathrm{~K}$, a peak $P F$ of $\sim 54 \mu \mathrm{W} \mathrm{cm}{ }^{-1} \mathrm{~K}^{-2}$ at $577 \mathrm{~K}$, which resulted in an engineering figure of merit $(Z T)_{\text {eng }}$ of $\sim 0.76$ and $(P F)_{\text {eng }}$ of $\sim 2.05 \mathrm{~W} \mathrm{~m}^{-1} \mathrm{~K}^{-1}$ for cold side fixed at $323 \mathrm{~K}$ and hot side at $723 \mathrm{~K}$.

Keywords: $\mathrm{Mg}_{2} \mathrm{Sn}_{0.75} \mathrm{Ge}_{0.25}$; Thermoelectric; High power factor; Carrier donor *corresponding author, email address: liuws@sustc.edu.cn; zren@uh.edu 


\section{Introduction}

Thermoelectric materials have attracted much attention due to its capability in directly converting waste heat from automobiles and industrial processes into electricity [1-5]. Thermoelectric power generator is also promising in utilization of solar energy [6-9]. One of the advantages of solar thermoelectric generation is its compatibility with relatively inexpensive thermal storage which could make power production around the clock [10]. The thermoelectric performance of a material is evaluated by a figure-of-merit $(Z T)$ regarding the local temperature point $(T)$ and the efficiency of a thermoelectric generator is more precisely determined by the engineering figure of merit $(Z T)_{e n g}$ regarding a global temperature range from $T_{c}$ to $T_{h}$. According to the new theoretical understanding, the conversion efficiency of a thermoelectric leg is loosely related to the local $Z T$, but tightly related to the global $(Z T)_{\text {eng }}[11,12]$.

$Z T=\frac{S^{2}}{\rho \kappa} T$

$(Z T)_{e n g}=\frac{\left(\int_{T_{C}}^{T_{H}} S(T) d T\right)^{2}}{\int_{T_{C}}^{T_{H}} \kappa(T) d T \int_{T_{C}}^{T_{H}} \rho(T) d T}\left(T_{H}-T_{C}\right)$

$\eta_{\text {max }}=\eta_{C} \frac{\sqrt{1+(Z T)_{\text {eng }}\left(\frac{\alpha_{1}}{\eta_{C}}\right)}-1}{\alpha_{0} \sqrt{1+(Z T)_{\text {eng }}\left(\frac{\alpha_{1}}{\eta_{C}}\right)}+\alpha_{2}}$

$\alpha_{i}=\frac{S\left(T_{H}\right)\left(T_{H}-T_{C}\right)}{\int_{T_{C}}^{T_{H}} S(T) d T}-\frac{\int_{C}^{T_{H}} \tau(T) d T}{\int_{T_{C}}^{T_{H}} S(T) d T} w_{T} \eta_{C}-i w_{J} \eta_{C}(i=0,1,2)$

where $S, \rho, \kappa, \tau, \eta_{C}, w_{T}, w_{J}$ are the Seebeck coefficient, electrical resistivity, total thermal conductivity, Thomson coefficient, Carnot efficiency, weight factor of Thomson heat, and weight factor of Joule heat, respectively. The calculation of the $w_{T}$ and $w_{J}$ were previously reported [12]. 
For practical applications, a high output power density is equally important as the efficiency since output power density is determined by the power factor [9]. Similarly, a global $(P F)_{e n g}$ is introduced,

$P F=\frac{s^{2}}{\rho}$

$(P F)_{e n g}=\frac{\left[\int_{T_{C}}^{T_{H}} S(T) d T\right]^{2}}{\int_{T_{C}}^{T_{H}} \rho(T) d T}$

$P_{d}=\frac{1}{4} \frac{\left(T_{H}-T_{C}\right)}{L_{l e g}}(P F)_{e n g}$

where $P_{d}$ is output power density and $L_{\text {leg }}$ the leg length. A high $(P F)_{\text {eng }}$ in a given temperature range requires a high local $P F$. It is well known that the local $P F$ at a given temperature for a semiconductor material is highly carrier concentration dependent [13-14]. The material with optimized local $P F$ usually falls into the degenerate range with a carrier concentration of at least $10^{19} \mathrm{~cm}^{-3}$. The high carrier concentration is usually achieved by extra doping of electrons, e.g., $\mathrm{Cl}$ in $\mathrm{PbSe}$ [15] and $\mathrm{P}$ in $\mathrm{Si}$ [16]) or holes, e.g., $\mathrm{Na}$ in $\mathrm{PbSe}$ [15] and $\mathrm{Al}$ in $\mathrm{Si}$ [16]. Doping by different elements at different sites has been extensively studied for many materials. For example, Te was a better dopant than $\mathrm{Ni}$ as n-type dopant at the $\mathrm{Sb}$ site in $\mathrm{CoSb}_{3}$ [17], $\mathrm{Al}$ doping in the $\mathrm{Pb}$ site in $\mathrm{PbSe}$ is better than the conventional Cl doping in the Se site [18].

$\mathrm{Mg}_{2} \mathrm{Sn}_{0.75} \mathrm{Ge}_{0.25}$ has recently been demonstrated as a promising thermoelectric material for power generation in the mid temperature range because of their high power factor over 50 $\mu \mathrm{W} \mathrm{cm}{ }^{-1} \mathrm{~K}^{-2}$ [11], in which $\mathrm{Sb}$ has been used as a dopant in the Sn site with donor capacity of $\sim 1$ carr./ atom. One of the reasons for the high power factor is the increased carrier band, and hence the enhanced density of state effective mass [11,19]. Furthermore, as compared with $\operatorname{Mg}_{2} \operatorname{Sn}_{1 \text { - }}$ ${ }_{\mathrm{x}} \mathrm{Si}_{\mathrm{x}}, \mathrm{Mg}_{2} \mathrm{Sn}_{0.75} \mathrm{Ge}_{0.25}$ showed weak electron scattering based on the estimated alloy deformation 
energy and hence higher power factor $[11,20]$. Besides $\mathrm{Sb}$ as a donor, other dopants, such as Bi, $\mathrm{Y}, \mathrm{La}, \mathrm{Al}$, and $\mathrm{Zn}$ were also reported in the $\mathrm{Mg}_{2} \mathrm{X}(\mathrm{X}=\mathrm{Sn}, \mathrm{Si}, \mathrm{Ge})$ based materials at either the Mg or X site [21-27]. Meng et al. reported that by electric field activated and pressure assisted synthesis, $\mathrm{Y}$ doping in the $\mathrm{Mg}$ site in $\mathrm{Mg}_{2} \mathrm{Si}$ has achieved a maximum power factor of $\sim 22 \mu \mathrm{W}$

$\mathrm{cm}^{-1} \mathrm{~K}^{-2}$ at $468 \mathrm{~K}$ [21]. By multi-doping of $\mathrm{Sb}, \mathrm{Al}$, and $\mathrm{Zn}$ to $\mathrm{Mg}_{2} \mathrm{Si}$, Zhao et al. achieved a maximum power factor of $\sim 33 \mu \mathrm{W} \mathrm{cm} \mathrm{K}^{-1} \mathrm{~K}^{-2}$ around $750 \mathrm{~K}$ using melting followed by spark plasma sintering [22]. Zhang et al. synthesized Sb doping for $\mathrm{Si}$ in $\mathrm{Mg}_{2} \mathrm{Si}$ using self-propagating high temperature synthesis followed by plasma activated sintering [28].

In this work, we systematically investigated the doping effect of $\mathrm{P}$ and $\mathrm{Bi}$ for $\mathrm{Sn}$ and $\mathrm{Y}$ and $\mathrm{La}$ for $\mathrm{Mg}$ of $\mathrm{Mg}_{2} \mathrm{Sn}_{0.75} \mathrm{Ge}_{0.25}$. It is found that the ionized donors at the $\mathrm{Sn}$-site have less electron scattering than the ones at $\mathrm{Mg}$-site. Furthermore, $\mathrm{Bi}$ is found to be more effective to provide extra electrons than $\mathrm{P}$.

\section{Experiment}

\subsection{Synthesis}

Magnesium turnings (Mg, 99.98\%; Alfa Aesar), tin powder (Sn, 99.8\%; Alfa Aesar), germanium powder (Ge, 99.99\%, Alfa Aesar), phosphorous pieces (P, 99.98\%; Alfa Aesar), bismuth shots (Bi, 99.999\%; Alfa Aesar), yttrium shots (Y, 99.99\%; Alfa Aesar), and lanthanum pieces (La, 99.99\%; Alfa Aesar) were weighted according to stoichiometries. To compensate the loss of $\mathrm{Mg}$ and adjust the carrier concentration, a 3 at\% extra $\mathrm{Mg}$ was added during the preparation process, similarly like what was reported by Uher et al. [29]. Under argon atmosphere inside a glovebox all the elements were loaded to a stainless steel ball milling jar with oxygen level below $1 \mathrm{ppm}$ and then sealed for ball milling for 20 hours (SPEX 8000D). The powders were then loaded into 
a graphite die with an inner diameter of $12.7 \mathrm{~mm}$ in a glove box and immediately hot pressed into bulk samples at $1023 \mathrm{~K}$ for 2 minutes with a temperature ramping up rate of $100 \mathrm{~K} / \mathrm{min}$.

\subsection{Characterization}

The resistivity and the Seebeck coefficient were measured under helium atmosphere by the thermoelectric characterization system (ZEM-3; ULVAC Riko). The thermal diffusivity $(D)$ is measured by laser flash method (LFA 457; Netzsch), and the specific heat $\left(c_{p}\right)$ is measured by differential scanning calorimetry (DSC $404 \mathrm{C}$; Netzsch). The density $(d)$ is measured by the Archimedes method. The thermal conductivity $k$ was calculated using $k=d D c_{p}$. The measurement errors of the electrical resistivity, Seebeck coefficient, and thermal conductivity are $\pm 3 \%, \pm 3 \%$, and $\pm 5 \%$, respectively. Hall coefficient $R_{H}$ was measured at $300 \mathrm{~K}$ using a commercial system (PPMS Dynacool; quantum design) with a four-probe method that consists of a magnetic field switching between $\pm 3 \mathrm{~T}$ and a current of 10-20 mA. To calculate the Hall carrier concentration $n_{\mathrm{H}}$ and the Hall mobility $\mu_{\mathrm{H}}, n_{\mathrm{H}}=1 /\left(e R_{H}\right)$ and $\mu_{\mathrm{H}}=R_{H} / \rho$ were used, respectively. The XRD diffraction was conducted on a PANalytical X'pert PRO diffractometer with a $\mathrm{Cu} \mathrm{K} \alpha$ radiation source. The microstructure of the fractured surfaces was studied by a scanning electron microscope (SEM, JEOL 6304F).

\section{Results}

The XRD patterns of all the doped samples are shown in the supplementary section (Fig. 1S-4S). $\mathrm{Bi}, \mathrm{P}$, and $\mathrm{Y}$ doped samples can be indexed according to the cubic anti-fluorite structure (space group $F m \overline{3} m$ ). For La doping, there is an impurity phase that is not identified. According to the 
microstructure of the fractured surfaces (Fig. S5), no notable pores are observable indicating that ball milling and hot pressing achieved high density. This is consistent with our density measurements $\left(3.47 \mathrm{~g} \mathrm{~cm}^{-3}, 99.1 \%\right.$ relative to the theoretical density). Fig. 1(a)-1(e) shows the temperature dependent thermoelectric properties of $\mathrm{Bi}$ doped $\mathrm{Mg}_{2} \mathrm{Sn}_{0.75-\mathrm{x}} \mathrm{Bi}_{\mathrm{x}} \mathrm{Ge}_{0.25}$. For the undoped $\mathrm{Mg}_{2} \mathrm{Sn}_{0.75} \mathrm{Ge}_{0.25}$ sample, the electrical resistivity decreased with the temperature (inset in 1a), indicating intrinsic semiconductor behavior. Bismuth, doping to the Sn site, made the system heavily degenerated. The electrical resistivity decreased by $~ 93 \%$ with a $1 \%$ Bi doping compared to the undoped sample, shown in Fig. 1(a). With increasing Bi doping, the electrical resistivity continuously decreased from $\sim 7.5 \mu \Omega \mathrm{m}(\mathrm{Bi}=1.0 \%)$ to $\sim 4.9 \mu \Omega \mathrm{m}(\mathrm{Bi}=3 \%)$ at room temperature. All the Bi doped samples showed negative Seebeck coefficients indicating n-type behavior, shown in Fig. 1(b). The Seebeck coefficient for all the Bi doped samples increased linearly with temperature till $675 \mathrm{~K}$ before saturation. With increasing $\mathrm{Bi}$ concentration, the Seebeck coefficient decreased in the whole temperature range indicating degenerated semiconductor behavior. Fig. 1(c) shows the calculated power factor of all the samples from the electrical resistivity shown in Fig. 1(a) and Seebeck coefficient shown in and Fig. 1(b). It is shown that the $2 \% \mathrm{Bi}$ doped sample has the highest power factor $\sim 45 \mu \mathrm{W} \mathrm{cm} \mathrm{K}^{-1}$ at room temperature and $\sim 54 \mu \mathrm{W} \mathrm{cm}{ }^{-1} \mathrm{~K}^{-2}$ at $576 \mathrm{~K}$, which is comparable with $\mathrm{Mg}_{2} \mathrm{Sn}_{0.73} \mathrm{Sb}_{0.02} \mathrm{Ge}_{0.25}$ in the whole temperature range [11]. Fig. 1(d) shows the total thermal conductivity with increasing Bi concentration. For all the samples the thermal conductivity decreased till $622 \mathrm{~K}$ and then increased due to the minority carrier excitation. Compared to the undoped samples the bipolar contribution was suppressed due to the increased carrier concentration (see the inset). The Seebeck coefficients tend to saturate near this temperature that confirms the minority carrier 
excitation. The highest $Z T$ of $\sim 1.4$ was achieved at $676 \mathrm{~K}$ in the $2 \% \mathrm{Bi}$ doped sample, shown in Fig. 1(e).

Fig. 1(f)-(j) shows the temperature dependent thermoelectric properties of $P$ doped $\mathrm{Mg}_{2} \mathrm{Sn}_{0.75-\mathrm{x}} \mathrm{P}_{\mathrm{x}} \mathrm{Ge}_{0.25}$. It is found that $\mathrm{P}$, was also a donor in the $\mathrm{Mg}_{2} \mathrm{Sn}_{0.75-\mathrm{x}} \mathrm{P}_{\mathrm{x}} \mathrm{Ge}_{0.25}$ system, and decreased the electrical resistivity and Seebeck coefficient as shown in Fig. 1(f) and (g). However, $\mathrm{P}$ is not nearly as effective as $\mathrm{Bi}$, which made the power factor, shown in Fig. 1(h) much lower than the Bi doped (Fig. 1(c)) and Sb doped (green line in Fig. 1(h)) samples. Due to the higher electrical resistivity, the total thermal conductivity is lower (Fig. 1(i)). As the result, the ZTs of all P doped samples are lower (Fig. 1(j)).

Fig. 2(a)-(e) shows the temperature dependent thermoelectric properties of $\mathrm{Y}$ doped $\mathrm{Mg}_{2-}$ ${ }_{\mathrm{x}} \mathrm{Y}_{\mathrm{x}} \mathrm{Sn}_{0.75} \mathrm{Ge}_{0.25}$. The electrical resistivity of all the $\mathrm{Y}$ doped samples showed a decrease with increasing temperature. At the same doping amount of $x=3 \%$, the room temperature electrical resistivity of the $\mathrm{Y}$ doped sample $(\sim 120 \mu \Omega \mathrm{m})$ is 24 times higher than that of the Bi doped sample $(\sim 5 \mu \Omega \mathrm{m})$. Higher doping amount of $\mathrm{Y}$ further reduced the electrical resistivity down to $\sim 63 \mu \Omega \mathrm{m}(4 \% \mathrm{Y})$ and $\sim 50 \mu \Omega \mathrm{m}(5 \% \mathrm{Y})$, but still much higher than the Bi and $\mathrm{P}$ doped samples, indicating that $\mathrm{Y}$ is not an efficient electron donor. Fig. 2(b) shows the temperature dependent Seebeck coefficient for the Y doped samples. A decrease in the Seebeck coefficient near room temperature was clearly observed with increasing doping, which is consistent with the decreased electrical resistivity. The calculated power factors for all the Y concentration have a weak temperature dependence, as shown in Fig. 2(c), but much lower than the Bi and Sb doped samples. Fig. 2(d) and Fig. 2(e) shows the temperature dependent total thermal conductivity and the $Z T$, respectively. With the total thermal conductivity not much lower than the $\mathrm{Bi}$ and $\mathrm{Sb}$ doped samples and a strong bipolar effect, the ZTs are much lower. 
In comparison, $\mathrm{La}$ is even worse than $\mathrm{Y}$ as an electron donor, shown in Fig. 2(f)-(j), resulting in similar electrical resistivity (Fig. 2(f)). However, with much lower Seebeck coefficients (Fig. 2(g)), leading to much lower power factors (Fig. 2(h)), plus even higher thermal conductivity (Fig. 2(i)), the ZTs are much lower (Fig. 2(j)).

As discussed above, the engineering $(P F)_{e n g}$ and $(Z T)_{e n g}$ have a tight relationship with the output power density and efficiency, respectively, Fig. 3(a) and (b) shows the calculated $(P F)_{e n g}$ and $(Z T)_{\text {eng }}$ with the same hot side temperature $\left(T_{H}\right)$ at $723 \mathrm{~K}$ and cold side temperature $\left(T_{C}\right)$ $323 \mathrm{~K}$ for all materials, but different optimized donor concentrations: $2 \%$ for $\mathrm{Bi}, 2 \%$ for $\mathrm{P}, 4 \%$ for Y, $5 \%$ for $\mathrm{La}$, and $2.2 \%$ for $\mathrm{Sb}$ [11]. The $(P F)_{\text {eng }}$ and $(Z T)_{\text {eng }}$ of $\mathrm{Mg}_{2} \mathrm{Sn}_{0.75} \mathrm{Ge}_{0.25}$ materials with all the other investigated doping concentrations are shown in Fig. S6-9. For the Bi doped samples, the highest engineering $(P F)_{323 K}^{723 K}$ is $\sim 2.05 \mathrm{~W} \mathrm{~m}^{-1} \mathrm{~K}^{-1}$, and engineering $(Z T)_{323 K}^{723 K}$ is $\sim 0.76$. The calculated output power density and efficiency using engineering $(P F)_{323 K}^{723 K}$ and engineering $(Z T)_{323 K}^{723 K}$ are shown in Fig. 3(c) and (d). Due to the reduced thermal conductivity in the Bi doped samples, the engineering $(Z T)_{323 K}^{723 K}$ is higher, which leads to a higher efficiency of $\sim 12 \%$ for the $\mathrm{Bi}$ doped samples instead of the $\sim 10 \%$ for the $\mathrm{Sb}$ doped samples, a real improvement that is meaningful for practical applications.

\section{Discussion}

The results from different dopants clearly show the differences especially between the VI group $(\mathrm{P}, \mathrm{Sb}$, and $\mathrm{Bi})$ and the rare-earth group $(\mathrm{Y}$ and $\mathrm{La})$. To figure out the mechanisms, carrier concentration was measured as shown in Fig 4. Theoretically calculated fully ionized line was also shown for comparison. Theoretically, it is assumed that each donor atom contributes one 
electron to the lattice. It is found that only $\mathrm{Bi}$ is close to the theoretical values, i.e., 1 carr./ atom [30]. However, when the doping concentration of $\mathrm{Bi}$ is over $\mathrm{x}=0.02$, it starts to deviate from the straight line, suggesting a saturation trend. Furthermore, for the same doping concentration of $\mathrm{x}$ $=0.02$, Bi donates fewer electrons $\left(\sim 1.6 \times 10^{20} \mathrm{~cm}^{-3}\right.$ for $\left.\mathrm{Mg}_{2} \mathrm{Sn}_{0.73} \mathrm{Ge}_{0.25} \mathrm{Bi}_{0.02}\right)$ than $\mathrm{Sb}(\sim 2.7 \times$ $10^{20} \mathrm{~cm}^{-3}$ for $\mathrm{Mg}_{2} \mathrm{Sn}_{0.73} \mathrm{Ge}_{0.25} \mathrm{Sb}_{0.02}$ [31]). As compared with the $\mathrm{Bi}$ and $\mathrm{Sb}, \mathrm{P}$ is a much weaker donor. On the other hand, both dopants $\mathrm{Y}$ and $\mathrm{La}$ at $\mathrm{Mg}$ site shows a comparable carrier concentration around $10^{19} \mathrm{~cm}^{-3}$ at a dopant amount of $\mathrm{x}=0.03$ in $\mathrm{M}_{\mathrm{x}} \mathrm{Mg}_{2-\mathrm{x}} \mathrm{Sn}_{0.75} \mathrm{Ge}_{0.25}$, which is one order of magnitude lower than that in $\mathrm{Bi}$ and $\mathrm{Sb}$ doped samples. It is noted that some impurity phases were identified in all the investigated $\mathrm{La}_{x} \mathrm{Mg}_{2-\mathrm{x}} \mathrm{Sn}_{0.75} \mathrm{Ge}_{0.25}$ samples, as shown in Fig. S4. Such impurities may also be responsible for the low Seebeck coefficient. It is noted that Zhang et al. reported that $\mathrm{La}$ has a very low solubility-limit in $\mathrm{Mg}_{2-\mathrm{x}} \mathrm{La}_{\mathrm{x}} \mathrm{Sn}_{58} \mathrm{Si}_{0.42}$ (less than 0.01), and some LaMg impurity phases [24].

Fig. 5(a)-(d) shows the dopant concentration dependent carrier mobility and effective mass for $\mathrm{Bi}, \mathrm{P}$, and $\mathrm{Y}$ doped $\mathrm{Mg}_{2} \mathrm{Sn}_{0.75} \mathrm{Ge}_{0.25}$. The DOS effective mass $\left(m_{d}{ }^{*}\right)$, the reduced Fermi energy $\left(\eta_{F}\right)$ and the Hall factor $\left(r_{H}\right)$ were calculated using Eqn. (5)-(8) by employing the single parabolic band (SPB) model under the relaxation time approximation assuming electrical transport is dominated by acoustic phonon scattering $(r=-1 / 2)$ [29-35],

$$
\begin{aligned}
& S=\frac{k_{B}}{e}\left(\eta-\frac{(5 / 2+r) F_{r+3 / 2}(\eta)}{(3 / 2+r) F_{r+1 / 2}(\eta)}\right) \\
& F_{i}(\eta)=\int_{0}^{\infty} \frac{x^{i} d x}{1+\exp (x-\eta)} \\
& \eta=\frac{E_{F}-E_{C}}{k_{B} T} \\
& n=\frac{2}{r_{H}}\left(\frac{2 \pi m^{*} k_{B} T}{h^{2}}\right)^{\frac{3}{2}} F_{\frac{1}{2}}(\eta)
\end{aligned}
$$


$r_{H}=\frac{3}{4} \frac{F_{\frac{1}{2}}(\eta) F_{\frac{-1}{2}}(\eta)}{F_{0}^{2}(\eta)}$

Where $\eta, F_{i}(\eta), r$, and $k_{B}$ are the reduced Fermi energy, the Fermi integral, the scattering factor, and the Boltzmann constant, respectively. Considering the effect of impurity phase, the calculated effective mass of $\mathrm{La}$ doped $\mathrm{La}_{\mathrm{x}} \mathrm{Mg}_{2-\mathrm{x}} \mathrm{Sn}_{0.75} \mathrm{Ge}_{0.25}$, based on a single band model for single phase, may not be accurate, since the real sample has impurities, so we only show it in the Supporting materials.

It is found that the mobilities of all samples decrease with increasing carrier concentration. For the $\mathrm{Bi}$ doped samples, both the mobility and the carrier concentration are much higher than that of the other doped samples. For $2 \% \mathrm{Bi}, 3 \% \mathrm{P}, 4 \% \mathrm{Y}$, and $5 \% \mathrm{La}$ the carrier motilities are $\sim 80, \sim 57, \sim 44$, and $\sim 8 \mathrm{~cm}^{2} \mathrm{~V}^{-1} \mathrm{~s}^{-1}$, respectively, at room temperature.

A high Seebeck coefficient at a given carrier concentration is attributed to a high DOS effective mass $\left(m_{d}{ }^{*}\right)$ [35]. For all the dopants the effective mass is plotted as a function of the dopant concentration in Fig. 5(d)-(f). The DOS effective mass can be defined as $N_{\mathrm{v}}{ }^{2 / 3} \mathrm{~m}_{\mathrm{b}}$, where $N_{\mathrm{v}}$ is the degenerate carrier pockets and $\mathrm{m}_{\mathrm{b}}$ is the average band mass [36,37]. Band flattening which corresponds to high $\mathrm{m}_{\mathrm{b}}$ causes the mobility to decrease [37]. However, the reason for the higher power factor here is the convergence of light band and heavy band to increase the $N_{\mathrm{v}}$ [11,31]. For $\mathrm{Bi}, \mathrm{P}$, and $\mathrm{Y}$ doping the effective mass is larger than $2 \mathrm{~m}_{0}$. With increasing dopant concentration, the effective mass of $\mathrm{Mg}_{2} \mathrm{Sn}_{0.75} \mathrm{Ge}_{0.25}$ shows an increasing trend. Only for the $\mathrm{Bi}$ doping the effective mass shows saturated characteristics at higher Bi concentration. $\mathrm{Bi}, \mathrm{P}$, and $\mathrm{Y}$ doping shows high effective mass compared to La doping. This high effective mass is consistent with the high Seebeck coefficient vs. temperature for Bi, P, and Y doping. 
The weighted mobility $(U)$ reflects the optimal electronic performance of a thermoelectric material [38-41]. It is defined as $\mu\left(m_{d} * / m_{\mathrm{e}}\right)^{3 / 2}$, where $m_{d} *$ is the density of states effective mass, $m_{e}$ is the mass of the electron and $\mu$ is the mobility of carriers. Fig. 6 shows the weighted mobility as function of the carrier concentration for $\mathrm{Bi}, \mathrm{P}$, and $\mathrm{Y}$ doped $\mathrm{Mg}_{2} \mathrm{Sn}_{0.75} \mathrm{Ge}_{0.25}$. Although it is normally expected that the weighted mobility carrier concentration is an independent constant of carrier concentration, but in our experiment, it is clearly shown that $U$ is still dependent on the ionized donors in $\mathrm{Mg}_{2} \mathrm{Sn}_{0.75} \mathrm{Ge}_{0.25}$. For $\mathrm{Bi}$ doping, the calculated weighted mobility ranges from 248 to $345 \mathrm{~cm}^{2} \mathrm{~V}^{-1} \mathrm{~s}^{-1}$ and for $\mathrm{P}$ doping it ranges from 261 to $268 \mathrm{~cm}^{2} \mathrm{~V}^{-1} \mathrm{~s}^{-1}$. The higher weighted mobility is the reason why Bi doped samples show higher power factor that the other samples.

\section{Conclusion}

Better thermoelectric properties have been demonstrated by doping $\mathrm{Bi}$ or $\mathrm{P}$ into $\mathrm{Sn}$ site in $\mathrm{Mg}_{2} \mathrm{Sn}_{0.75} \mathrm{Ge}_{0.25}$ than $\mathrm{Y}$ or La into $\mathrm{Mg}$ site. The results clearly suggest that in order to get the optimized carrier concentration and better thermoelectric properties, doping to the Sn site is much more effective than into the $\mathrm{Mg}$ site. Bi doped samples achieved a maximum engineering

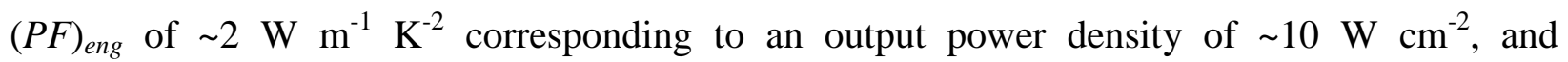
engineering $(Z T)_{\text {eng }}$ of $\sim 0.76$, corresponding to an efficiency of $12 \%$.

\section{Acknowledgements}

The work performed at the University of Houston is supported by the Solid State Solar-Thermal Energy Conversion Center ( $\left.\mathrm{S}^{3} \mathrm{TEC}\right)$, an Energy Frontier Research Center funded by the U.S. Department of Energy, Office of Science, Office of Basic Energy Sciences under Award Number: DE-SC0001299. 


\section{References}

[1] M. Telkes, Solar thermoelectric generators, J. Appl. Phys., 1954, 25, 765-777.

[2] C. Dent, M. Cobble, A solar thermoelectric generator experiments and analysis, 4th Int. Conf. on Thermoelectric Energy Conversion, 1982.

[3] F. Suarez, A. Nozariasbmarz, D. Vashaee, M.C. Ozturk, Designing Thermoelectric Generators for Self-Powered Wearable Electronics, Energy Environ. Sci., 2016, 9, 20992113.

[4] L.D. Zhao, V.P. Dravid, M.G. Kanatzidis, The panoscopic approach to high performance thermoelectrics, Energy Environ. Sci., 2014, 7, 251-268.

[5] L.E. Bell, Cooling, heating, generating power, and recovering waste heat with thermoelectric systems, Science, 2008, 321, 1457-1461.

[6] J. Karni, Solar energy. The thermoelectric alternative, Nat. Mater., 2011, 10, 481-482.

[7] D. Kraemer, B. Poudel, H.P. Feng, J.C. Caylor, B. Yu, X. Yan, Y. Ma, X. Wang, D. Wang, A. Muto, K. McEnaney, M. Chiesa, Z. Ren, G. Chen, High-performance flat-panel solar thermoelectric generators with high thermal concentration, Nat. Mater., 2011, 10, 532-538.

[8] S. Su, J. Chen, Simulation Investigation of High-Efficiency Solar Thermoelectric Generators With Inhomogeneously Doped Nanomaterials, IEEE Trans. Ind. Electron., 2015, 62, 3569-3575.

[9] W. Liu, H.S. Kim, Q. Jie, Z. Ren, Importance of high power factor in thermoelectric materials for power generation application: A perspective, Scr. Mater., 2016, 111, 3-9.

[10] A. Pereira, T. Caroff, G. Lorin, T. Baffie, K. Romanjek, S. Vesin, K. Kusiaku, H. Duchemin, V. Salvador, N. Miloud-Ali, High temperature solar thermoelectric generatorIndoor characterization method and modeling, Energy, 2015, 84, 485-492.

[11] W. Liu, H.S. Kim, S. Chen, Q. Jie, B. Lv, M. Yao, Z. Ren, C.P. Opeil, S. Wilson, C.W. $\mathrm{Chu}, \mathrm{Z}$. Ren, n-type thermoelectric material $\mathrm{Mg}_{2} \mathrm{Sn}_{0.75} \mathrm{Ge}_{0.25}$ for high power generation, Proc. Natl. Acad. Sci. U. S. A., 2015, 112, 3269-3274.

[12] H.S. Kim, W. Liu, G. Chen, C.W. Chu, Z. Ren, Relationship between thermoelectric figure of merit and energy conversion efficiency, Proc. Natl. Acad. Sci. U. S. A., 2015, 112, 285293.

[13] G.J. Snyder, E.S. Toberer, Complex thermoelectric materials, Nat. Mater., 2008, 7, 105114.

[14] G. Alekseeva, E. Gurieva, P. Konstantinov, L. Prokof'eva, M. Fedorov, Thermoelectric figure of merit of hetero-and isovalently doped PbSe, Semiconductors, 1996, 30, 11251127.

[15] H. Wang, Y. Pei, A.D. LaLonde, G.J. Snyder, Heavily Doped p-type PbSe with High Thermoelectric Performance: An Alternative for PbTe, Adv. Mater., 2011, 23, 13661370.

[16] O. Yamashita, Effect of metal electrode on Seebeck coefficient of p-and n-type Si thermoelectrics, J. Appl. phys., 2004, 95, 178-183.

[17] J.W. Sharp, E.C. Jones, R.K. Williams, P.M. Martin, B.C. Sales, Thermoelectric properties of $\mathrm{CoSb}_{3}$ and related alloys, J. App. phys., 1995, 78, 1013-1018.

[18] Q. Zhang, H. Wang, W. Liu, H. Wang, B. Yu, Q. Zhang, Z. Tian, G. Ni, S. Lee, K. Esfarjani, Enhancement of thermoelectric figure-of-merit by resonant states of aluminium doping in lead selenide, Energy Environ. Sci., 2012, 5, 5246-5251. 
[19] J. Mao, W. Liu, Z. Ren, Understanding Carrier Distribution in Multi-Band Materials and Its Effect on Thermoelectric Properties, Materiomics, 2016, 2, 203-211.

[20] J. Mao, H.S. Kim, J. Shuai, Z. Liu, R. He, U. Saparamadu, F. Tian, W. Liu, Z. Ren, Thermoelectric properties of materials near the band crossing line in $\mathrm{Mg}_{2} \mathrm{Sn}-\mathrm{Mg}_{2} \mathrm{Ge}-$ $\mathrm{Mg}_{2} \mathrm{Si}$ system, Acta Mater., 2016, 103, 633-642.

[21] Q. Meng, W. Fan, R. Chen, Z. Munir, Thermoelectric properties of Sc-and Y-doped $\mathrm{Mg}_{2} \mathrm{Si}$ prepared by field-activated and pressure-assisted reactive sintering, J. Alloys Compd., 2011, 509, 7922-7926.

[22] J. Zhao, Z. Liu, J. Reid, K. Takarabe, T. Iida, B. Wang, U. Yoshiya, S.T. John, Thermoelectric and electrical transport properties of $\mathrm{Mg}_{2} \mathrm{Si}$ multi-doped with $\mathrm{Sb}, \mathrm{Al}$ and Zn, J. Mater. Chem. A, 2015, 3, 19774-19782.

[23] J.E. Lee, S.H. Cho, M.W. Oh, B. Ryu, S.J. Joo, B.S. Kim, B.K. Min, H.W. Lee, S.D. Park, Enhancement of thermoelectric properties of $\mathrm{Mg}_{2} \mathrm{Si}$ compounds with $\mathrm{Bi}$ doping through carrier concentration tuning, Electron. Mater. Lett., 2014, 10, 807-811.

[24] Q. Zhang, J. He, X.B. Zhao, S.N. Zhang, T.J. Zhu, H. Yin, T.M. Tritt, In situ synthesis and thermoelectric properties of La-doped $\mathrm{Mg}_{2}(\mathrm{Si}, \mathrm{Sn})$ composites, J. Phys. D: Appl. Phys., 2008, 41, 185103.

[25] J. Tani, H. Kido, Thermoelectric properties of Bi-doped $\mathrm{Mg}_{2} \mathrm{Si}$ semiconductors, Physica B, 2005, 364, 218-224.

[26] T. Sakamoto, T. Iida, A. Matsumoto, Y. Honda, T. Nemoto, J. Sato, T. Nakajima, H. Taguchi, Y. Takanashi, Thermoelectric Characteristics of a Commercialized $\mathrm{Mg}_{2} \mathrm{Si}$ Source Doped with Al, Bi, Ag, and Cu, J. Electron. Mater., 2010, 39, 1708-1713.

[27] H. Gao, T. Zhu, X. Zhao, Y. Deng, Influence of Sb doping on thermoelectric properties of $\mathrm{Mg}_{2} \mathrm{Ge}$ materials, Intermetallics, 2015, 56, 33-36.

[28] Q. Zhang, X. Su, Y. Yan, H. Xie, T. Liang, Y. You, X. Tang, C. Uher, Phase segregation and superior thermoelectric properties of $\mathrm{Mg}_{2} \mathrm{Si}_{1-\mathrm{x}} \mathrm{Sb}_{\mathrm{x}}(0 \leq \mathrm{x} \leq 0.025)$ Preaperd by Ultrafast Self-Propagating High-Temperature Synthesis, ACS Appl. Mater. Interfaces, 2016, 8, 32653276.

[29] W. Liu, Q. Zhang, K. Yin, H. Chi, X. Zhou, X. Tang, C. Uher. High figure of merit and thermoelectric properties of Bi-doped $\mathrm{Mg}_{2} \mathrm{Si}_{0.4} \mathrm{Sn}_{0.6}$ solid solutions, J. Solid State Chem., 2013, 203, 333-339.

[30] Q. Zhang, L. Cheng, W. Liu, Y. Zheng, X. Su, H. Chi, H. Liu, Y. Yan, X. Tang, C. Uher, Low effective mass and carrier concentration optimization for high performance p-type $\mathrm{Mg}_{2(1-\mathrm{x})} \mathrm{Li}_{2 \mathrm{x}} \mathrm{Si}_{0.3} \mathrm{Sn}_{0.7}$ solid solutions, Phys. Chem. Chem. Phys., 2014, 16, 23576-23583.

[31] W. Liu, J. Zhou, Q. Jie, Y. Li, H.S. Kim, J. Bao, G. Chen, Z. Ren, New insight into the material parameter $B$ to understand the enhanced thermoelectric performance of $\mathrm{Mg}_{2} \mathrm{Sn}_{1-\mathrm{x}-}$ ${ }_{\mathrm{y}} \mathrm{Ge}_{\mathrm{x}} \mathrm{Sb}_{\mathrm{y}}$, Energy Environ. Sci., 2016, 9, 530.

[32] J. Tani, H. Kido, Thermoelectric properties of Al-doped $\mathrm{Mg}_{2} \mathrm{Si}_{1-\mathrm{x}} \mathrm{Sn}_{\mathrm{x}}$, J. Alloys Compd., 2008, 466, 335-340.

[33] J. de Boor, S. Gupta, H. Kolb, T. Dasgupta, E. Müller, Thermoelectric transport and microstructure of optimized $\mathrm{Mg}_{2} \mathrm{Si}_{0.8} \mathrm{Sn}_{0.2}$, J. Mater. Chem. C, 2015, 3, 10467-10475.

[34] T. Dasgupta, C. Stiewe, J. de Boor, E. Mueller, Influence of power factor enhancement on the thermoelectric figure of merit in $\mathrm{Mg}_{2} \mathrm{Si}_{0.4} \mathrm{Sn}_{0.6}$ based materials, Phys. Status Solidi A, 2014, 211, 1250-1254.

[35] X. Liu, T. Zhu, H. Wang, L. Hu, H. Xie, G. Jiang, G.J. Snyder, X. Zhao, Low Electron Scattering Potentials in High Performance $\mathrm{Mg}_{2} \mathrm{Si}_{0.45} \mathrm{Sn}_{0.55}$ Based Thermoelectric Solid 
Solutions with Band Convergence, Adv. Energy Mater., 2013, 3, 1238-1244.

[36] W. Liu, H. Chi, H. Sun, Q. Zhang, K. Yin, X. Tang, Q. Zhang, C. Uher, Advanced thermoelectrics governed by a single parabolic band: $\mathrm{Mg}_{2} \mathrm{Si}_{0.3} \mathrm{Sn}_{0.7}$, a canonical example, Phys. Chem. Chem. Phys., 2014, 16, 6893-6897.

[37] Y. Pei, H. Wang, G.J. Snyder, Band Engineering of Thermoelectric Materials, Adv. Mater., 2012, 24, 6125-6135.

[38] J. Zhang, L. Song, G.K. Madsen, K.F. Fischer, W. Zhang, X. Shi, B.B. Iversen, Designing high-performance layered thermoelectric materials through orbital engineering, Nat. commun., 2016, 7, 10892.

[39] Y. Pei, X. Shi, A. LaLonde, H. Wang, L. Chen, G.J. Snyder, Convergence of electronic bands for high performance bulk thermoelectrics, Nature, 2011, 473, 66-69.

[40] J. Mao, Y. Wang, B. Ge, Q. Jie, Z. Liu, U. Saparamadu, W. Liu and Z. Ren, Thermoelectric performance enhancement of $\mathrm{Mg} 2 \mathrm{Sn}$ based solid solutions by band convergence and phonon scattering via $\mathrm{Pb}$ and $\mathrm{Si} / \mathrm{Ge}$ substitution for Sn, Phys. Chem.Chem. Phys., 2016, 18, 20726-20737.

[41] A.M. Dehkordi, M. Zebarjadi, J. He, T.M. Tritt, Thermoelectric power factor:Enhancement mechanisms and strategies for higher performance thermoelectric materials, Mater. Sci. Eng., $R, 2015,97,1-22$. 


\section{Figure captions}

Figure 1. The thermoelectric properties of $\mathrm{Bi}$ doped $\mathrm{Mg}_{2} \mathrm{Sn}_{0.75-x} \mathrm{Bi}_{x} \mathrm{Ge}_{0.25}$ (a-e) and $\mathrm{P}$ doped $\mathrm{Mg}_{2} \mathrm{Sn}_{0.75-x} \mathrm{P}_{x} \mathrm{Ge}_{0.25}(\mathrm{f}-\mathrm{j})$.

Figure 2. The thermoelectric properties of $\mathrm{Y}$ doped $\mathrm{Mg}_{2-x} \mathrm{Y}_{x} \mathrm{Sn}_{0.75} \mathrm{Ge}_{0.25}$ (a-e) and La doped $\mathrm{Mg}_{2-x} \mathrm{La}_{x} \mathrm{Sn}_{0.75} \mathrm{Ge}_{0.25}(\mathrm{f}-\mathrm{j})$.

Figure 3. (a) $(P F)_{e n g}$, (b) $(Z T)_{e n g}$, (c) output power density, and (d) efficiency of $2 \% \mathrm{Bi}, 2 \% \mathrm{P}$, $4 \% \mathrm{Y}$, and $5 \% \mathrm{La}$ doped samples with hot side temperature $T_{H}=723 \mathrm{~K}$ and cold side temperature $\mathrm{T}_{\mathrm{c}}=323 \mathrm{~K}$ for $\mathrm{Mg}_{2} \mathrm{Sn}_{0.75} \mathrm{Ge}_{0.25}$.

Figure 4. (a) Carrier concentration vs. Bi concentration, (b) carrier concentration vs. P concentration, (c) carrier concentration $v s$. Y concentration, (d) carrier concentration $v s$. La concentration.

Figure 5. (a) The mobility $v s$. Bi content, (b) the mobility $v s . \mathrm{P}$ content, (c) the mobility $v s . \mathrm{Y}$ content, (d) the effective mass $v s$. Bi content, (e) the effective mass $v s$. P content, and (f) the effective mass $v s$. Y content.

Figure 6. Weighted mobility vs. carrier concentration of $\mathrm{Bi}, \mathrm{P}, \mathrm{Y}, \mathrm{La}$ and $\mathrm{Sb}$ doped $\mathrm{Mg}_{2} \mathrm{Sn}_{0.75} \mathrm{Ge}_{0.25}$. 
Figure 1.
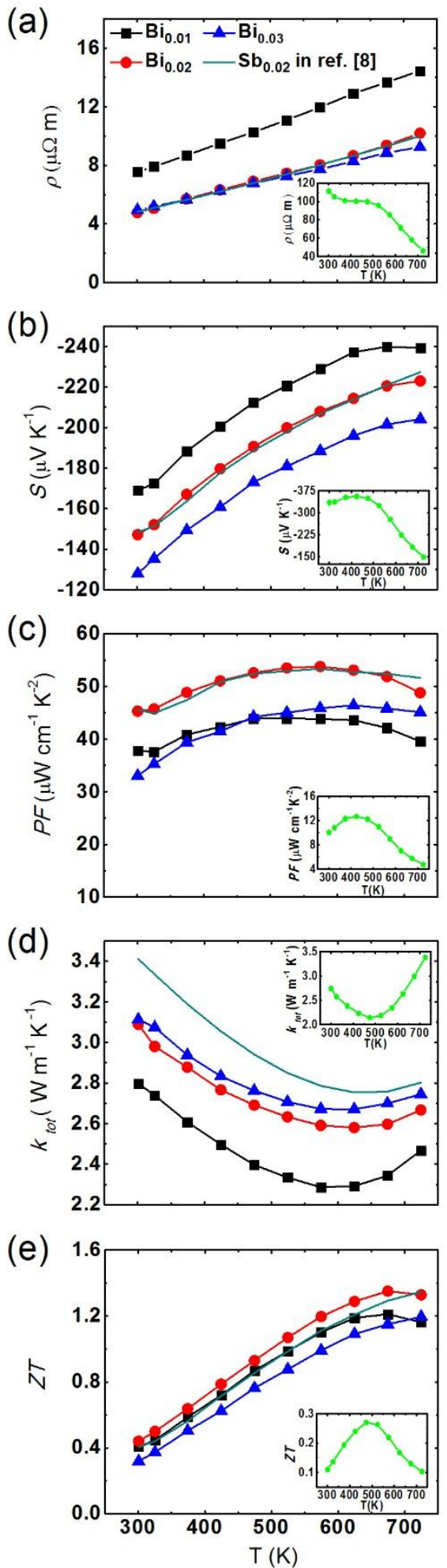
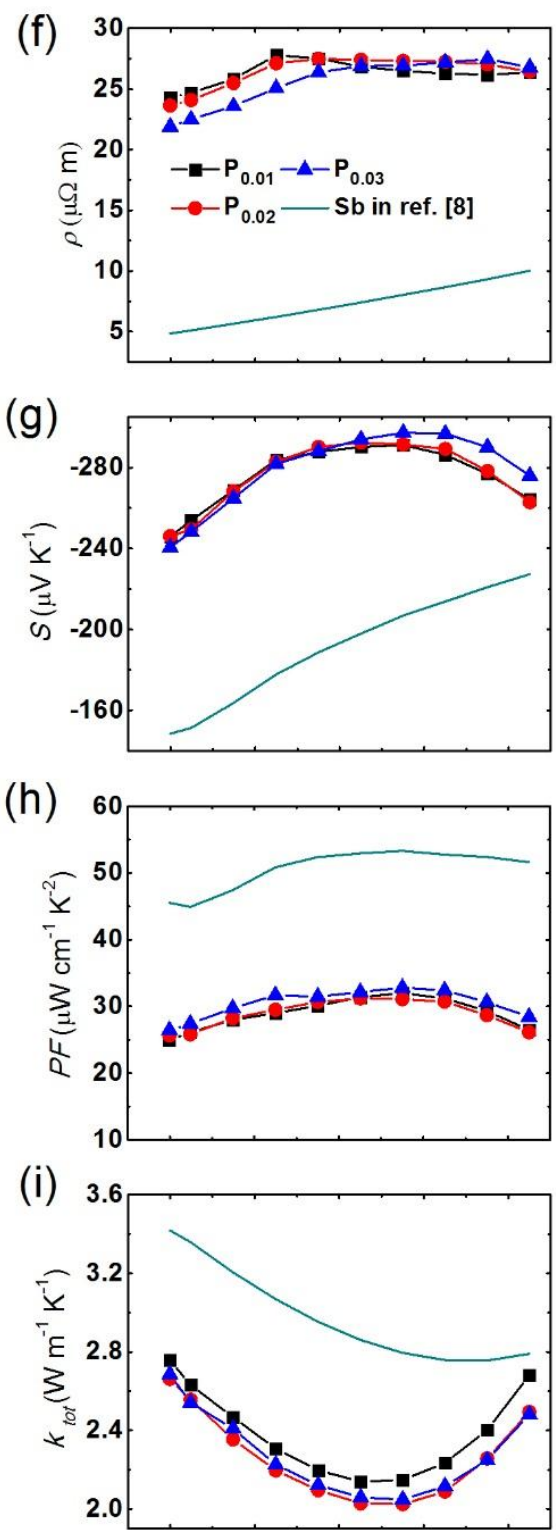

(j)

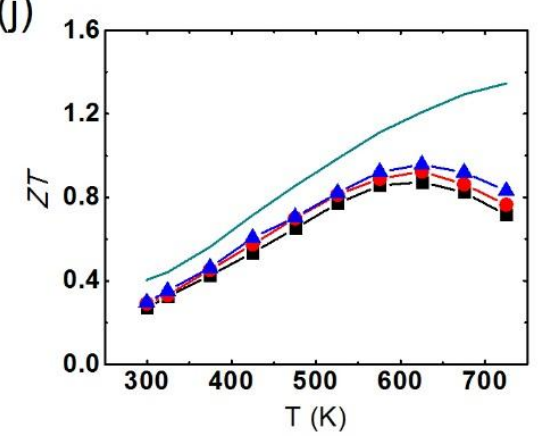


Figure 2.
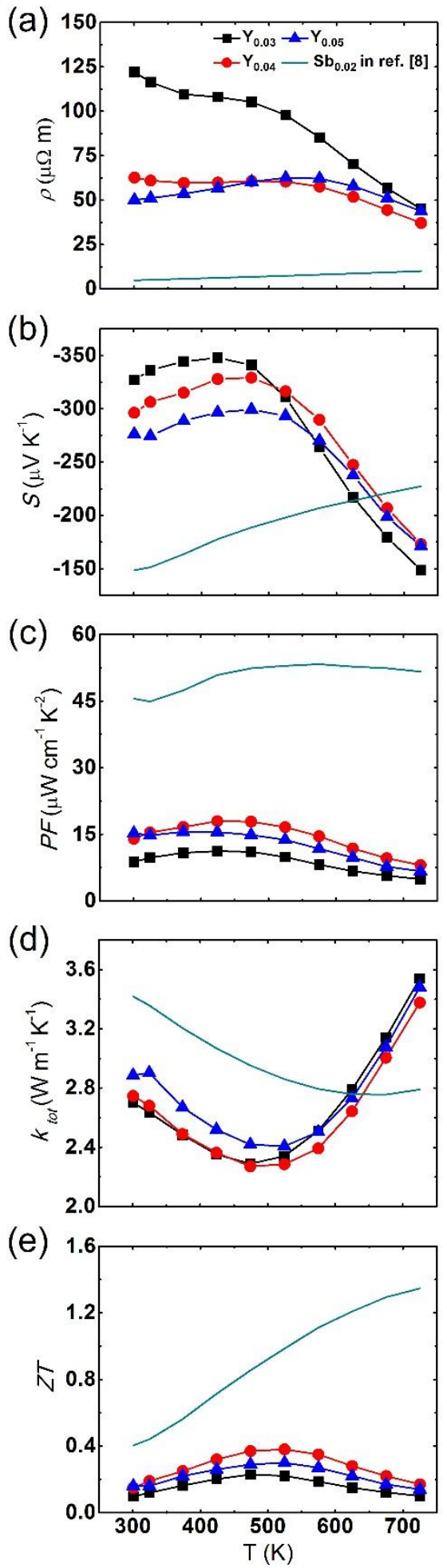
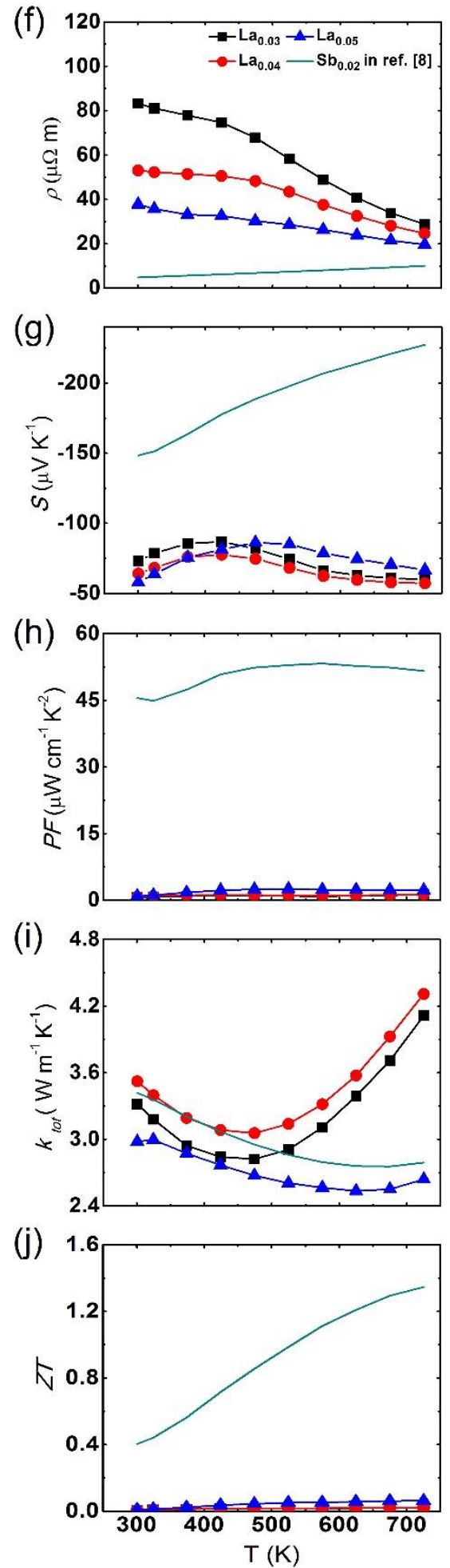
Figure 3. (a)

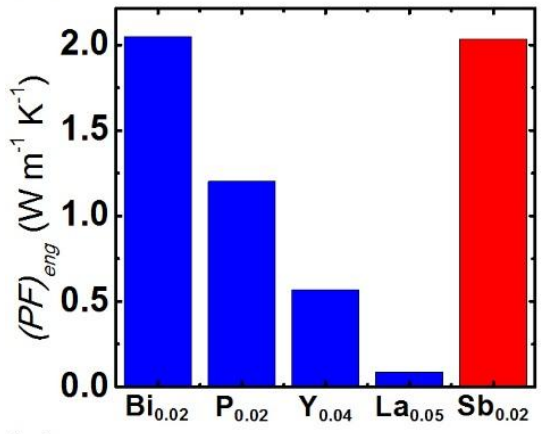

(c)

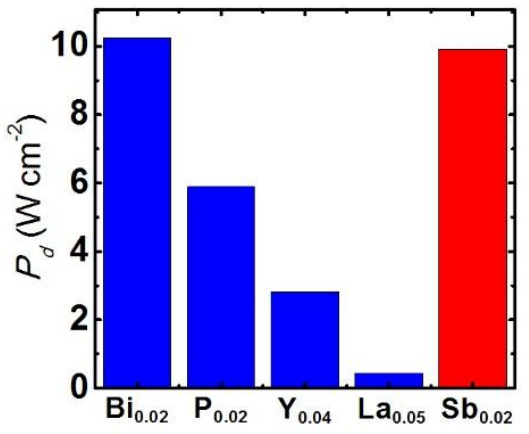

(b)

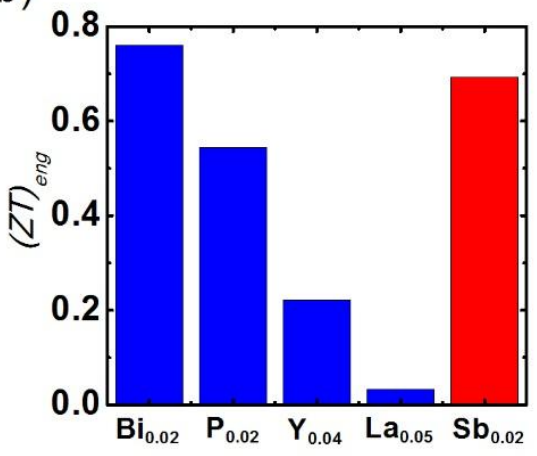

(d)

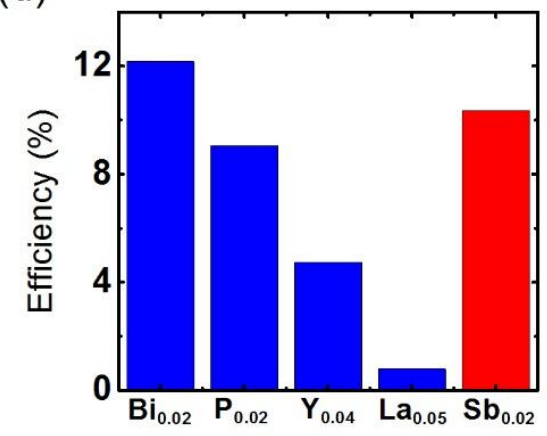


Figure 4.

(a)

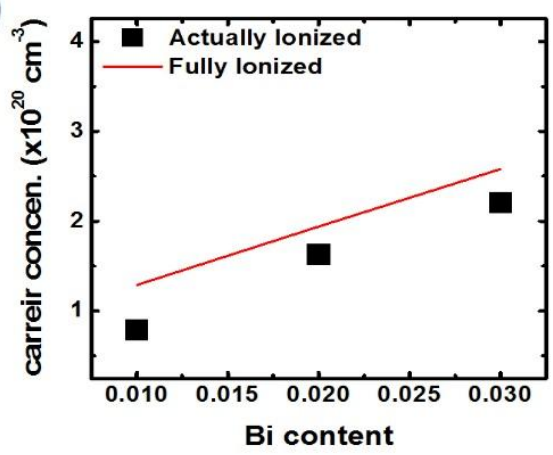

(c)

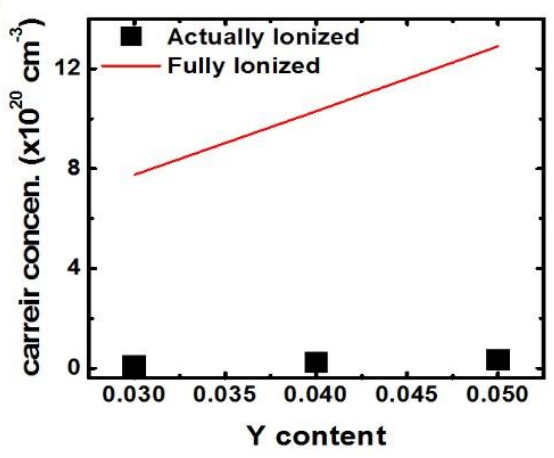

(b)

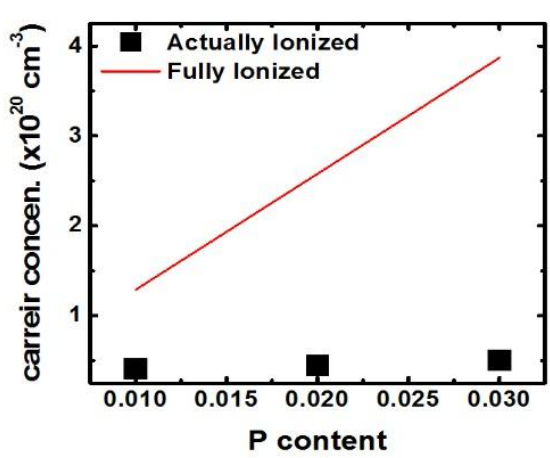

(d)

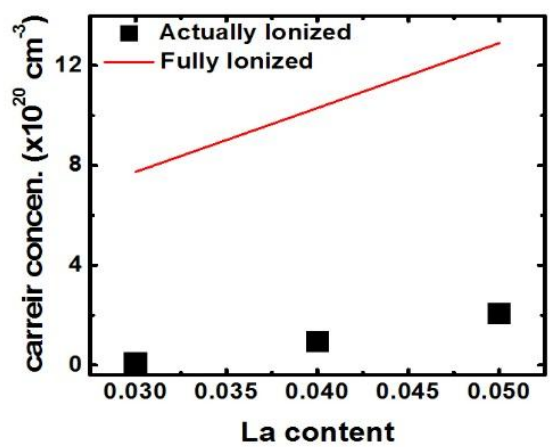


Figure 5.
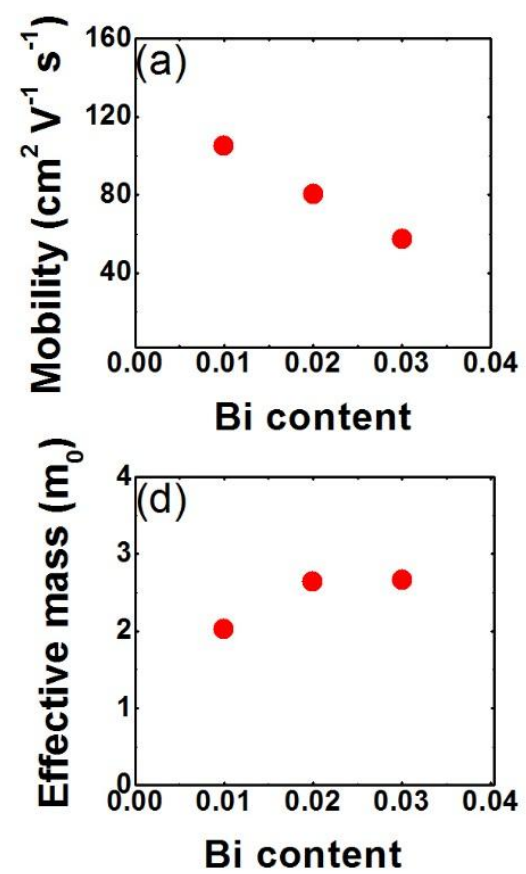
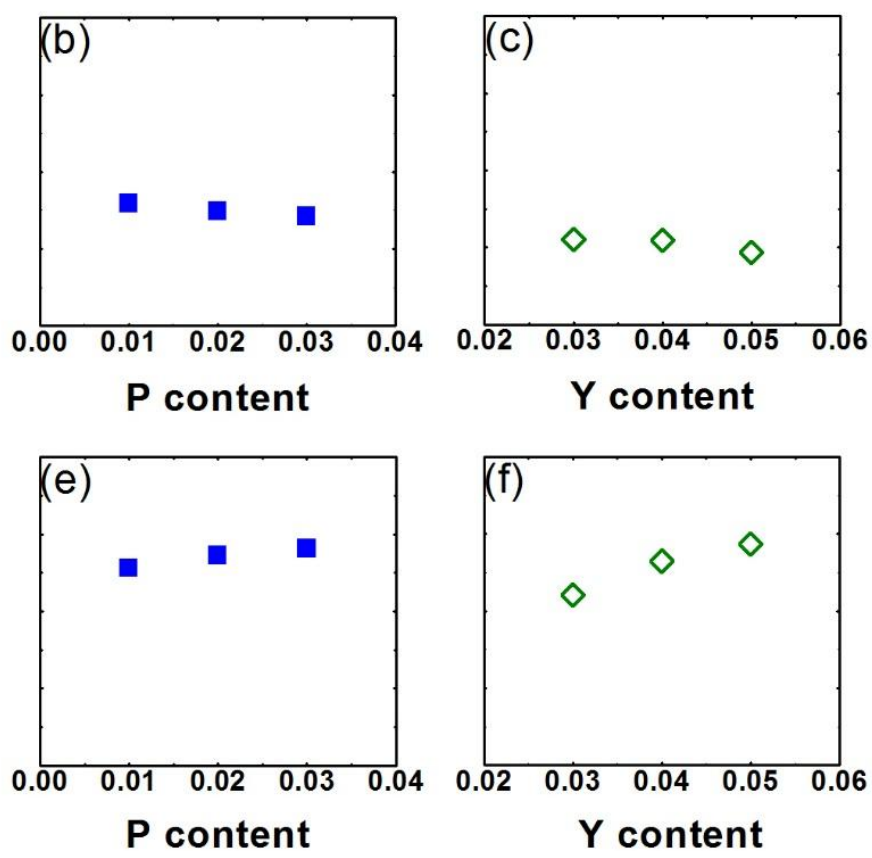
Figure 6.

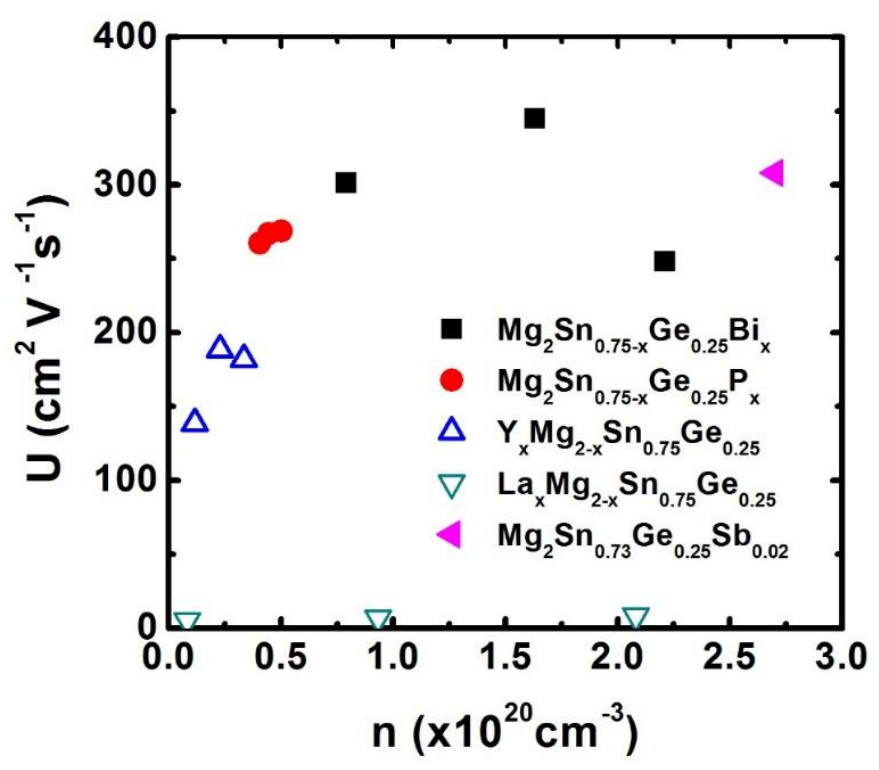




\section{Graphical Abstract}

(a)

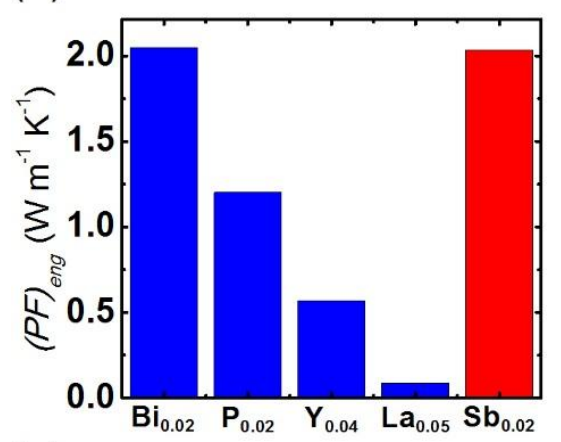

(c)

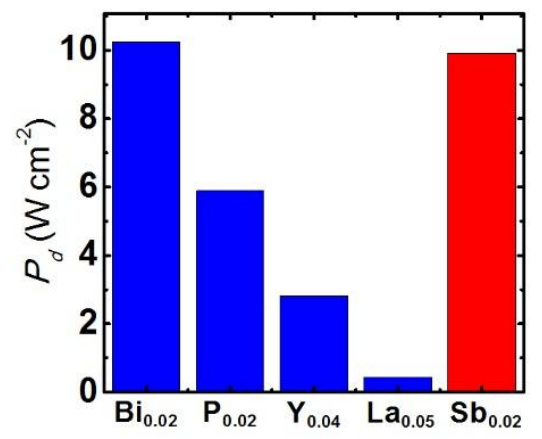

(b)

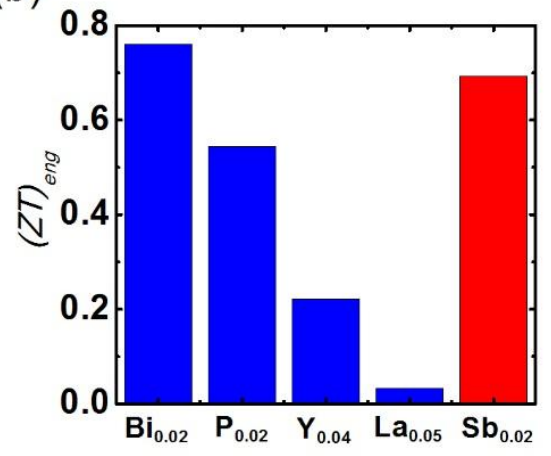

(d)

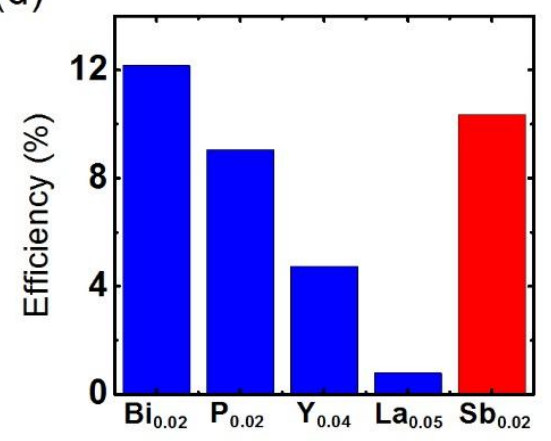

